\title{
The development of smart screening technology kit (SST-Kit) for sorting cassava cultivars based on cyanide analysis
}

\author{
Luluil Maknun ${ }^{1}$, Noerma Juli Azhari ${ }^{1}$, Mike Nur Izzati ${ }^{1}$, Rizal Nur Huda ${ }^{1}$, Abdul Malik Bahruddin $^{1}$, Erliana \\ Ginting ${ }^{2}$, Hermin Sulistyarti ${ }^{1 *}$ \\ ${ }^{1}$ Faculty of Science, Brawijaya University \\ Jln. Veteran Malang, Ketawanggede, Kec. Lowokwaru, Kota Malang 65145, East Java, Indonesia \\ ${ }^{2}$ Indonesian Legumes and Tuber crops Research Istitute (ILETRI) \\ Malang 65101, East Java, Indonesia \\ *Corresponding author: hermin@ub.ac.id
}

Received: $5^{\text {th }}$ June 2016; Revised: $11^{\text {th }}$ February 2020; Accepted: $14^{\text {th }}$ February 2020

\section{Keywords:}

Cassava, cyanide content,fast-screening method, ninhydrin, SST-Kit,

\begin{abstract}
Cyanides are deadly toxic substances commonly found in cassava root tuber. Higher content of cyanides causes bitter taste of the root tuber. Therefore, analysis of cyanide content has been used as one of criteria for bitterness in cassava. The substitute common method used for this purpose was organoleptic test that could lead to poisoning, or argentometry, which is complicated, time-consuming, and requires lots of reagents. Therefore, a fast, easy, and safe method is strongly demanded. In this work, a smart screening technology kit (SST-Kit) was developed using ninhydrin reagent. This simple, fast, and low-cost method can be applied in the field for the analysis of cyanide levels in cassava. This method was optimized to the concentration of sodium carbonate from 0.5 to $2.0 \%$ by measuring the red color intensity produced under various times of reading from 1 to 3 minutes and three sample preparation techniques. The optimum condition for SST-Kit to read the cyanides level was achieved under the condition of $0.5 \%$ of sodium carbonate with a time readout of 2 minutes, using grinding preparation technique followed by dilution. The SST-kit had been applied on cassava samples with the accuracy of more than $90 \%$.
\end{abstract}

\section{INTRODUCTION}

Cyanide is a toxic substance which occurs in cassava as cyanogenic glucoside. Cyanide can be found in a number type of foods and plants, such as bitter almonds, milled sprouts, soy, spinach, bamboo shoots and cassava (Taylor et al., 2010; Jackson and Brian, 2017). Various cultivars of cassava can be classified based on their cyanide concentration level; bitter cassava (cyanide level $>50 \mathrm{mg} \cdot \mathrm{L}^{-1}$ ) and sweet cassava (cyanide level $<50 \mathrm{mg} \cdot \mathrm{L}^{-1}$ ) (Ginting and Widodo, 2013). The lethal dose of cyanide for human body is $0.5-3.5 \mathrm{mg}$ per $\mathrm{kg}$ in weight and 2 $\mathrm{mg}$ per kg in body weight of animal, especially cattle and sheep (Hlaing et al., 2011; Yildiz et al., 2017). Due to the limit concentration of cyanide allowed in human body and their potential toxicity to the surrounding environment, the high concentration of cyanide in cassava should be strongly considered. Therefore, monitoring cyanide in cassava, especially for constrain is required.

The common method used for cyanide analysis based on the association of official analytical chemists (AOAC) is argentometric method. Despite its high accuracy, it is time-consuming, involves complicated procedure, and requires technical skills. Another usual method for cyanide analysis in the major society is organoleptic test (Onyesom et al., 2008). A manual test is used as a qualitative analysis to clasify the bitter and sweet cassava by the method of tasting. Thus, this organoleptic test can harm the body due to cyanide poisoning impact. A 


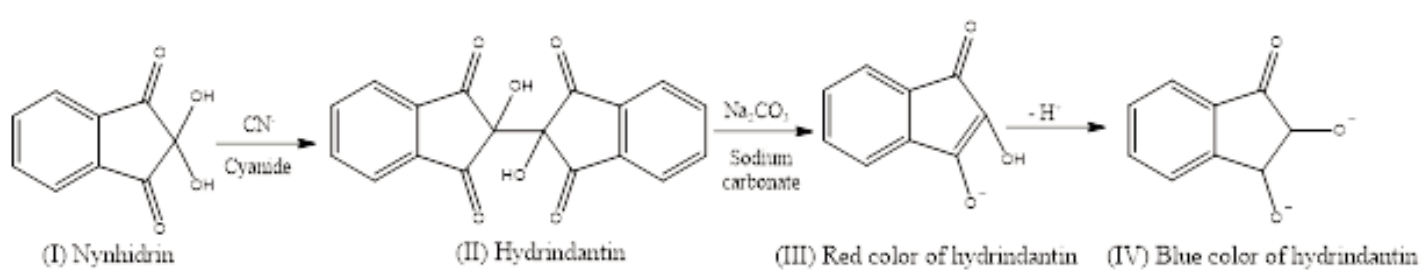

Figure 1. Reaction squence for the formation of red or blue-colored product (Nagaraja et al., 2002).

rapid and sensitive method based colorimetric sensor gain attracts more attention for cyanide analysis in food and agriculture product. However most of these sensors have complicated multi-step procedures (Niu et al., 2018; Niu et al., 2018). For these reasons, SST-Kit, a simple procedure method was developed for on-site analysis of cyanide in cassava. The smart screening technology (SST) kit was also proposed to open a new access in developing method for agricultural analysis.

SST kit was developed based on the formation of hydrindantin complex which appears in red color at $\mathrm{pH} 8-10$ and in blue color at pH $12.0-12.8$; such reaction is shown in Figure 1 . The intensity of the complex formed in the reaction is proportional to the concentration of cyanide (Nagaraja et al., 2002). In the previous work performed by Drochioiu et al. (2004), cyanide analysis was analysed based on the presence of blue color or purple color regarding the hydrindantin formation (2-cyano-1,2,3-trihydroxy-2H indene). This method was succesfully developed because the interference, such as copper, silver, and mercury ions, was elucidated. However, the low stability of the intensity color complex of hydrindantin was the drawback of this essay (Surleva et al., 2013). In the present work, the method was developed based on the formation of the red color of hydrindantin.

The red color of hydrindantin is formed by the reaction between cyanide and ninhydrin in sodium carbonate medium. Some factors affecting the intensity of red color are the concentration of sodium carbonate, the concentration of ninhydrin solution, $\mathrm{pH}$, and the reaction time (Hlaing et al. 2011, Mihaescu and Drochioiu, 2009; Abdalla and Safwan, 2007). Previously, it has been reported by Nagaraja et al. (2002) that the formation of red color was stable when using $1 \%(\mathrm{w} / \mathrm{v})$ of ninhydrin with the reaction time of 30 minutes in the presence of $5 \%$ sodium carbonate $(\mathrm{pH}$ range in between 8-12). In this research, some factors mentioned above were studied including the time of reading to obtain the optimum condition of stable complex formation.

Cyanide in cassava is present mainly as a cyanogenic glucoside ( $95 \%$ linamarin compound). In most analytical methods, linamarin is hydrolysed in acid or base to produce hydrogen cyanide that can be detected via sensitive reaction, like colorimetric method (Ginting dan Widodo, 2013; Bradbury et al., 1991). Therefore, in this method, sample preparation was required to liberate cyanide from glucocyanide. In order to enhance the hydrolisis reaction product, cassava sample was prepared using a certain design. The stability and sensitivity of the proposed method were investigated by applying SST kit to detect the cyanide in the real sample of cassava. Furthermore, SST-kit was directly applied for on-site analysis of cyanide as the consideration to sort out cassava before distributing it to the market or for other uses.

\section{MATERIALS AND METHODS}

The materials used in this study were Pottasium cyanide powder (Sigma-Aldrich, St. Louis, USA), pottasium carbonate (Merck, Damstadt, Germay), ninhydrin (Sigma-Aldrich, St.Louis, USA) and deionized water, obtained from a water purification system $\left(18.2 \mathrm{M} \Omega . \mathrm{cm}^{-1}\right)$. All reagents used were dissolved in deionized water. Cassava tubers were obtained from Indonesian Legumes and Tuber crops Research Institute, Malang, East Java, Indonesia. Two tubers of each cultivar were CMM 6 and Adira 1 (sweet cassava). One tuber of the cassava cultivars was the local variety obtained from local market, Malang, East Java, Indonesia. All of the cassava cultivars (CMM 6, Adira 1 and Local cassava) were tested by using SST-kit for cyanide contained to determine the sweetness or bitterness of the cassava variety.

A double-beam UV/Vis spectrometer with 1-cm matched cells of quartz was used for absorbance measurement (UV-Vis, Shimadzu, Japan). A commercial digital camera of smartphone was used for visual detection of cyanide in the solution. The paper strips 
(Photo papers KL100MSHR) were used for digital image visualization of color comparator scale.

\section{Optimization of cyanide test kit}

The condition for determining cyanide using SST-Kit was optimized with respect to the concentration of $\mathrm{Na}_{2} \mathrm{CO}_{3}$ which was varied from $0.5 \%$ to $2 \%(\mathrm{w} / \mathrm{v})$. Each concentration of $\mathrm{Na}_{2} \mathrm{CO}_{3}$ was added into the test tube containing various cyanide solutions of 0.00 ; 0.04 ; 0.08 ; and $0.10\left(\mathrm{mg}^{-1} \mathrm{~L}^{-1}\right)$ followed by adding 2 drops of $1 \%(\mathrm{w} / \mathrm{v})$ ninhydrin, mixed, and read at the absorbance of the red color of $480 \mathrm{~nm}$. The optimum concentration of $\mathrm{Na}_{2} \mathrm{CO}_{3}$ was determined in the highest absorbance. Such a concentration was then used to determine the stability of hydrindantin formation at various time-reading of 1,2 , and 3 minutes.

\section{Construction of standard color for cyanide detection}

Color comparator is the series of colors used for determining cyanide obtained from series standard solutions after the reaction with SST-Kit reagents. The color comparator was made by mixing pottasium cyanide solution (concentration of $0.00,0.02,0.04$, $0.06,0.08,0.10$, and $0.30 \mathrm{mg}^{-\mathrm{L}^{-1}}$ ) with optimum concentration of $\mathrm{Na}_{2} \mathrm{CO}_{3}$ followed by the addition of two drops of $1 \%$ ninhydrin. The red colored solution produced from the reaction was captured by camera under the optimum time of reading, on which the color was converted from yellow to red, indicating the presence of cyanide in the solution.

\section{Sample Preparation for cyanide detection in cassava}

In order to produce the high hydrolysis product of hydrogen cyanide which can enhance the sensitivity and accuracy of SST-kit, sample preparation was

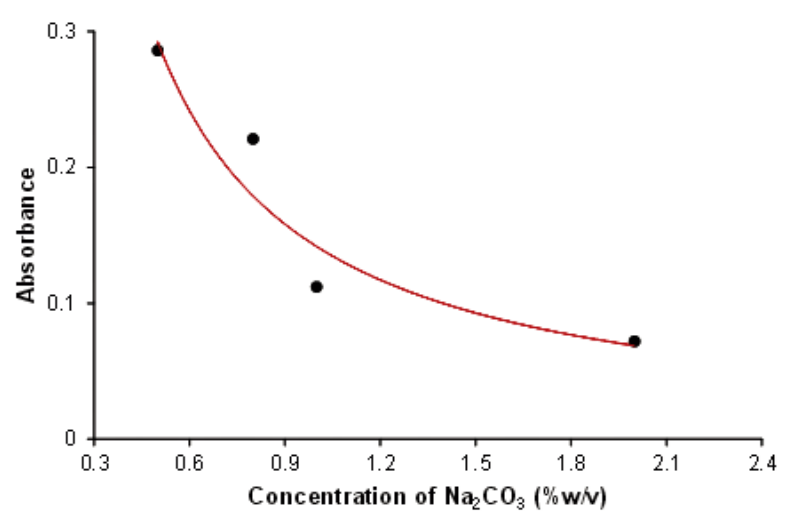

Figure 2. The absorbance of hydrindantin at various concentration of $\mathrm{Na}_{2} \mathrm{CO}_{3}$ conducted in three differents methods: (i) the cassava was sliced in small pieces; (ii) the cassava was grinded in $\mathrm{Na}_{2} \mathrm{CO}_{3}$ solution; and (iii) the cassava was grinded and added with $\mathrm{Na}_{2} \mathrm{CO}_{3}$ solution after the grinding process. $1 \mathrm{~g}$ of cassava (sweet cassava) from each preparation method was analyzed using SST-kit and the result was compared with argentometric method.

\section{Validation of SST-kit by comparison with argento- metric method}

Validation was done by application of SST-kit to determine the presence of cyanide in three different cultivars of cassava (a) Local cassava (unknown sample); (b) CMM 6 (sweet cassava); and (c) Adira 1 (sweet cassava). The cyanide content in the 3 cultivars of cassava obtained from SST kit were compared with those obtained from standard argentometric method. The cyanide concentration observed from SST-kit and argentometric method was validated by paired t-test method to check the reliability and reproducibility of SST-kit.

\section{RESULTS AND DISCUSSION}

\section{Effect of reagent concentration and time-reading to the intensity of red hydrindantin}

Parameters affecting the sensitivity of the SSTKit was studied based on the monitoring of red color formation of hydrindantin. To perform these experiments, various concentration of $\mathrm{Na}_{2} \mathrm{CO}_{3}$ were used as the first optimization. As clearly shown in Figure 2, the absorbance of hydrindantin complex got increased as the concentration of $\mathrm{Na}_{2} \mathrm{CO}_{3}$ got

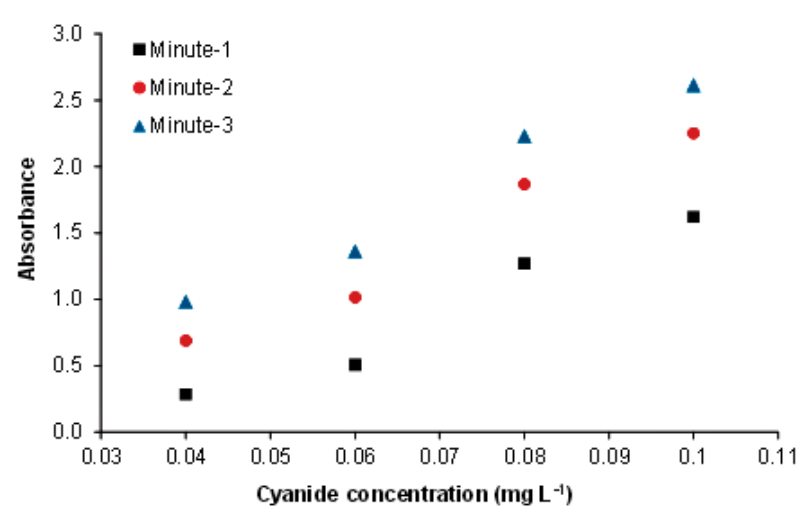

Figure 3. The absorbance of red hydrindantion at various timereading 
decreased. The optimum absorbance of hydrindantin complex was achieved under $0.5 \%(\mathrm{w} / \mathrm{v})$ of sodium carbonate which provided a strong intensity of the red color that can be detected visually to the naked eyes. This result was also supported by highest sensitivity values observed from each $\mathrm{Na}_{2} \mathrm{CO}_{3}$

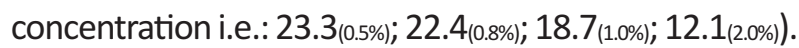

Under optimum condition of $\mathrm{Na}_{2} \mathrm{CO}_{3}$ concentration $(0.5 \% \mathrm{w} / \mathrm{v})$, the stability of red hydindantin was monitored at different time-reading as illustrated in the Figure 2. As shown in Figure 2, the absorbance gets increased due to the increasing of cyanide concentration. The time-reading test shows that in the second minute, the optimum reaction took place between cyanide and ninhydrin to form the hydrindantin complex. In the second minute, the linearity of the slope presented in Figure 3 was better compared in the first and third minute. Another plousible reason was the clear differentiation of red color intensity formed in the solution between each concentration as supported in the Table 1 . At the $2^{\text {nd }}$ and $3^{\text {rd }}$ minute, the red color of solution was more intensed than in the first minute. The differences of red color in the solution is revealed in Table 1.

Based on the result shown in Table 1, the second minute was selected as optimum time-reading as the red color formed can be clearly distinguished among difference cyanide concentrations. As the previous experiment performed by Abdalla et al. (2007) using flow system method, the increasing of delay time means the reaction between cyanide and nynhidrin in the system before going to detector; the absorbance becomes increased and directly constant at longer delay time (10 - $15 \mathrm{~min}$.). The increasing of absorbance means that the intensity of the colored product periodically increased. The results showed that the medium reaction time ( 5 minutes) was selected in their work due to stable formation of the red colored product.

\section{Standard color comparator for cyanide detection}

The optimum parameters mentioned in the previous part, $0.5 \%$ of $\mathrm{Na}_{2} \mathrm{CO}_{3}$ and 2-minute reading, were selected to design standard colour comparator. The colour comparator was made on the paper strip showing concentration of cyanide solution $\left(\mathrm{mg}^{-\mathrm{L}^{-1}}\right)$ : $0.00 ; 0.02 ; 0.04 ; 0.06 ; 0.08 ; 0.1 ; 0.3$. To construct the colour comparator design, $1.5 \mathrm{~mL}$ of cyanide solution prepared in $0.5 \% \mathrm{Na}_{2} \mathrm{CO}_{3}$ was transfered into the test tube and mixed with 2 drops of ninhydrin. After 2 minutes, the color formed in the test tube was captured by camera in suitable position. The construction of color comparator is represented in Figure 4.

\section{Application of SST-kit to determine cyanide concentration in the various cultivars of cassava}

As mentioned earlier, to extract the maximum hydrogen cyanide as a hydrolisis product of linamarin, three different preparation methods for sample

Table 1. The color of Hydrindantin under various time-reading

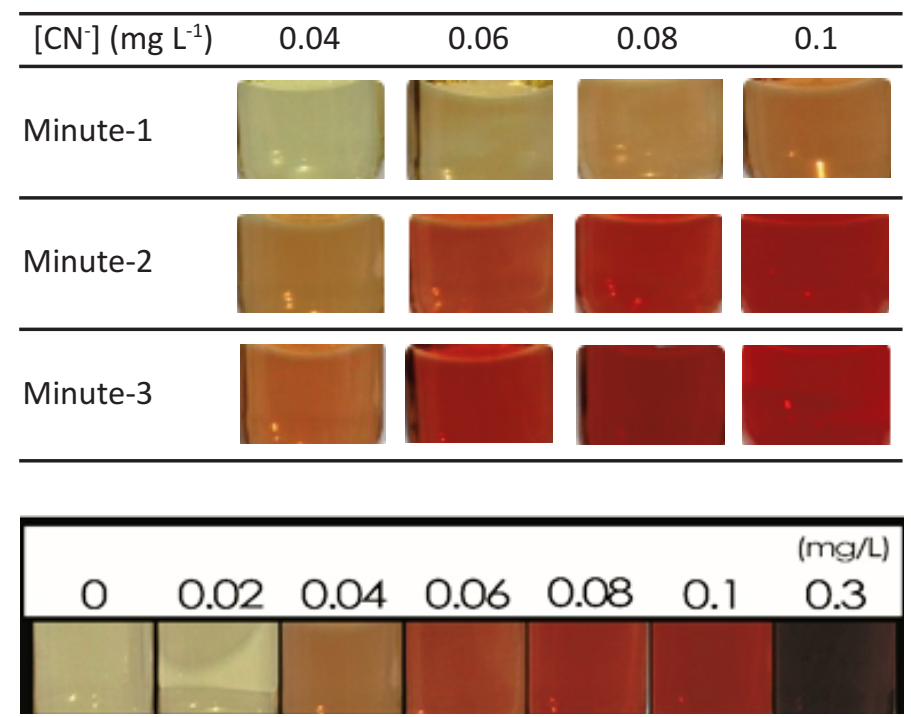

Figure 4. The colour comparator scale on the paper strip 


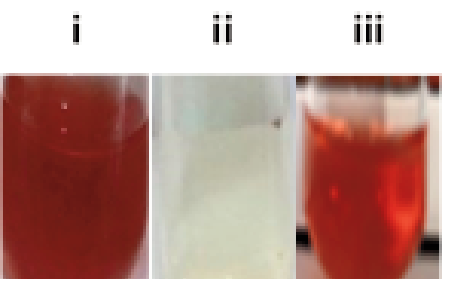

Figure 5. Sample preparation of tuber cassava in different method
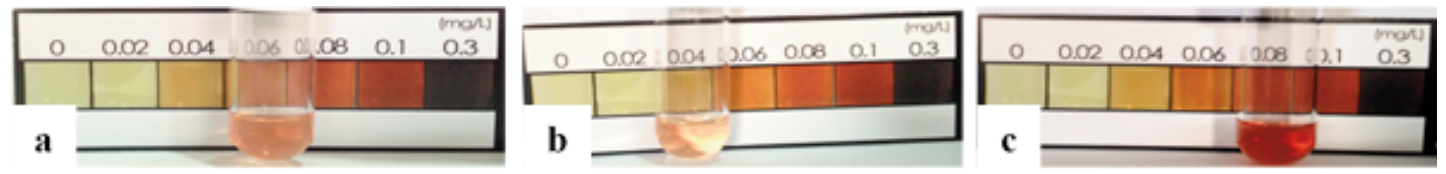

Figure 6. SST-kit application for cyanide detection of three cultivars of cassava : (a) Local; (b) CMM 6; (c) Adira 1 with triplicate expertiments $(n=3)$

Table 2. Comparison of cyanide concentration observed from SST-kit and argentrometric method

\begin{tabular}{lccccc}
\hline & \multicolumn{3}{c}{ Cyanide concentration $\left(\mathrm{mg} \mathrm{L}^{-1}\right)$} & & \\
\cline { 2 - 3 } Sample Code & $\begin{array}{c}\text { Concentration } \\
\text { from color } \\
\text { reading of kit }\end{array}$ & $\begin{array}{c}\text { Concentration } \\
\text { of SST-kit }\end{array}$ & $\begin{array}{c}\text { Argentometric } \\
\text { method }\end{array}$ & $\begin{array}{c}\text { Type of } \\
\text { cassava }\end{array}$ & \% recovery \\
\hline A (Local) & 0.06 & 9.9 & $10.3 \pm 0.5$ & Sweet & $96.1 \%$ \\
B (CMM 6) & 0.04 & 4.4 & $5.4 \pm 0.8$ & Sweet & $81.5 \%$ \\
C (Adira 1) & 0.08 & 25.0 & $23.8 \pm 1.1$ & Sweet & $95.2 \%$ \\
\hline
\end{tabular}

handling were carried out and the results are shown in Figure 5. The sample preparation of (i) slicing and (iii) grinding without sodium carbonate was suitable to apply for cyanide detection in the real sample. Only sample preparation (ii) did not change the color of solution to the red hydrindantin. The reasonable explanation was that sodium carbonate which provided base condition inhibited linamarase activity in the hydrolisis linamarin. Theoritically, this enzyme works optimally at pH 5 (Ginting and Widodo, 2013). Due to the turbidity observed from sample preparation (i), sample preparation (iii) was more applicable as it gave transparent color. These results show that the transparent color can achieve high selectivity and sensitivity of the method for cyanide detection in cassava. In further step, three cultivars of cassava were examined for the cyanide content using SST-kit under the best sample preparation. The results from three cultivars are presented in Figure 6.

Application of SST-kit as shown in Figure 6 was conducted by weighing 20 grams of grinded cassava, followed by the dilution of sample in $0.5 \% \mathrm{Na}_{2} \mathrm{CO}_{3}$ solution with dilution factor of 200-times. According to the Table 2, cyanide from the three cultivars had a concentration of lower than $50 \mathrm{mg} . \mathrm{L}^{-1}$ meaning that all cultivars were sweet cassava. To check the validity of the proposed method, the result obtained from SST-kit was compared with the results from argentrometric method by statistic t-test method. The cyanide concentrations observed from SST-kit were close to the values from the argentometric method.

Based on the results from Table 2, the concentration of cyanide found in Adira 1 was higher than that in CMM 6 and local cassava. Looking at the concentration of cyanide, the bitterness of cassava increased when the cyanide concentration increased. The cyanide level found by our method was in good agreement with what was mentioned by Ginting and Widodo (2013). The cassava cultivars (mainly sweet cultivars) are mostly good for direct consumption. CMM is a good clone for cooking as it has low cyanide content, compared to Adira. It has been reported that Adira 1 is included in low cyanide content $\left(<50 \mathrm{mg}^{\mathrm{kg}}{ }^{-1}\right)$, 
but the level of bitterness is still higher than CMM. The cyanide level found in adira 1 is still below than what is found in Adira 4 which is included as bitter cassava due to high cyanide content $\left(68 \mathrm{mg} \cdot \mathrm{kg}^{-1}\right)$ (Sundari et al. 2000).

Using statistic t-test, the critical value (tcritical) was 4.30 at $P=0.05$ and the experimental calculated value (tcal) was 0.1 . The results indicated that there was no significant diffference in cyanide concentration in the cassava from the two techniques because tcal value was less than tcritical value. Thus, the developed method can be used as the alternative method for screening cyanide in cassava.

\section{CONCLUSIONS}

A sampling technique with a safe sample preparation for cyanide detection in cassava has been developed. The red colors formed have been studied spectrophotometrically under controlled $\mathrm{pH}$ and reaction time. The developed method for cyanide analysis designed in this study allowed the detection of cyanide in the range of $0.04-0.3 \mathrm{mg} \cdot \mathrm{L}^{-1}$ and it has been successfully applied to detect cyanide in the cassava. Owing to its rapidity, userfriendliness and timesaving, the SST-kit may be applied for cyanide control in food product.

\section{ACKNOWLEDGMENTS}

We are thankful for the Ministry of Research, Technology and Higher education (RISTEKDIKTI) for providing financial research support and for the Brawijaya University in providing full research facilities. We also would like to thank Indonesian Legumes and Tuber crops Research Institute (ILETRI) for supplying the cassava and for their helpful advice throughout the research process.

\section{REFERENCES}

Abdalla, M. and M.F. Sofwan. 2007. Sequential injection spectrophotometric determination of cyanide, J. Flow Injection Anal., 24: 17 - 21.

Bradbury, J.H., S.V. Egan, and M.J. Lynch. 1991. Analysis of cyanide in cassava using acid hydrolysis of cyanogenic glucosides. J.Sci.Food Agric., 55:277-290.

Drochioiu, G., I. Mangalagiu, E. Avram, K. Popa, A.C. Dirtu and I. druta. 2004. Cyanide reaction with ninhydrin: elucidation of reaction and interference mechanisms. Anal. Sci., 20: 1443-1447.

Ginting, S., and Y. Widodo. 2013. Cyanide reduction in cassava root product through processing and selection of cultivars in relation to food safety. Buletin Palawija 25: 25-36.

Hlaing, A., K. Naing, S.S. Myint, and Y.M. Aung. 2011. Study on the reaction between ninhydrin and cyanide and its analytical applications. Universities Research J., 4: 283 - 300.

Jackson, R. and B. A. Logue. 2017. A review of rapid and field-portable analytical techniques for the diagnosis of cyanide exposure. Anal. Chim. Acta. 960: 18-39.

Mihaescu, I.M. and G. Droichioiu. 2009. Cyanide reaction with ninhydrin : the effect of ph changes and uv-vias radiation upon the analytical results. Rev. Roum. Chim., 54: 841-845.

Nagaraja, P., M.S. Kumar, H.S. Yathirajan, and J.S. Prakash. 2002. Novel sensitive spectrophotometric method for the trace determination of cyanide in industria effluent. Anal. Sci., 18: 1027-1030.

Niu, Q., L. Lan, T. Li, Z. Guo, T. Jiang, Z. Zhao, Z. Feng and J. Xi. J. S. 2018. A highly selective turn-on fluorescent and naked-eye colorimetric sensor for cyanide detection in food samples and its application in imaging of living cells. 
Sensor Actuat. B-Chem., 276: 13-22.

Niu, Q., T. Sun, T. Li, Z. Guo and H. Pang. 2018. Highly sensitive and selective colorimetric/fluorescent probe with aggregation induced emission characteristics for multiple targets of copper, zinc and cyanide ions sensing and its practical application in water and food samples. Sensor Actuat. B-Chem., 266: 730-743.

Onyesom, I., P. Okoh and O.V. Okpokunu. 2008. Levels of cyanide in cassava fermented with Lemon Grass (Cymbopogon citratus) and the organoleptic assessment of its food products. World Appl. Sci. J., 4: 860-863.

Sundari, T.; K. Hartojo; Sholihin and E. Ginting. 2000. Identification and characterization of cassava clones for good taste purposes. p.217-223. In
A.A. Rahmiana, J. Soejitno, D.M. Arsyad, Heriyanto, Sudaryono, Suharsono and I.K. Tastra (eds). Bogor : Source Management of Legume and Tuber Crops. CRIFC. (in Indonesian). Surleva, A., S. Bancila, and E.V. Todorova. 2013. A study on ninhydrin reaction with weak acid dissociable cyanide and its application for toxic cyanide determination. Int. J. Environ. Anal. Chem., 2: $1-6$.

Taylor, J., N. Roney, C. Harper, M.E. Fransen, and S. Swarts. 2006. Toxicological profile for cyanide. U.S. Department of Health and human services, https://stacks.cdc.gov/view/cdc/6950.

Yildiz, K., B. Dokuzeylul, R. Gonul and M. Erman. 2017. Cyanide poisoning in cattle. J. Dairy and Veterinary Sci., 4: 1-3. 